\title{
Los indios rarámuris (tarahumaras de México) y las libertades
}

\section{The Rarámuris Indians (Tarahumaras of Mexico) and the freedoms}

\section{Patrick Allouette Montagnier*}

* Investigador de AMERIBER (América Latina, Países Ibéricos) de la Université Bordeaux Montaigne (Francia). Es doctor en Estudios Ibéricos y Latinoamericanos por la Université de Perpignan Via Domitia (Francia), docente con plaza obtenida en examen nacional por concurso de oposición, académico en instituciones de educación secundaria de la Rectoría de Niza. Especializado en las civilizaciones de México (s. XVII-XXI), en particular en la historia de los ferrocarriles. Investiga sobre las prácticas educativas. Miembro de la Sociedad de Hispanistas Franceses y del Equipo de traducción de Debates por la Historia. Calificado maestro de conferencias por la CNU. Correo electrónico patrick.allouette@u-bordeaux-montaigne.fr

https://orcid.org/0000-0003-2830-069X

\section{Historial editorial}

Recibido: 12-diciembre-2018

Aceptado: 08-febrero-2019

Publicado: 29-abril-2019 
Los indios rarámuris (tarahumaras de México) y las libertades

\section{Resumen}

Para empezar, este artículo intenta aprehender la noción de libertad entre los indios tarahumaras de México según su propia concepción. Este preliminar establecido, hace una síntesis, desde la colonización hasta nuestros días, de las libertades perdidas, luego rescatadas, adquiridas y reconquistadas. Después, a partir de los resultados de investigaciones en terreno dirigidas a tarahumaras migrantes hacia Ciudad Cuauhtémoc, Chihuahua, hace un balance en la actualidad de esas libertades; antes de concluir proponiendo perspectivas y soluciones que se les ofrecen a los diferentes actores: sociólogos, antropólogos, investigadores, así como a los miembros de esta etnia. Finalmente se exponen las consecuencias de la escolarización, los adelantos y unos puntos de vista de antropólogos acerca de mexicanización; se recuerdan las importaciones tecnológicas y, respecto a las migraciones, se presenta, en contrapunto, el caso de Ciudad Juárez.

Palabras clave: México, tarahumaras, libertades, aculturación, resiliencia 
The Rarámuris Indians (Tarahumaras of Mexico) and the freedoms

\begin{abstract}
This article attempts to explain the concept of freedom among the Tarahumaras Indians of Mexico from their own perspective. It summarizes the ways in which freedom was lost, rescued, acquired and recovered from the period covered during the Mexican colonization until today. Then, based on the results of field research with Tarahumaras who migrated to Cuauhtémoc city in Chihuahua, it displays a current assessment of these freedoms. It also proposes perspectives and solutions to sociologists, anthropologists, researchers and members of this ethnic group. In addition, it presents the consequences of schooling, social progress and technology, as well as the points of view of anthropologists regarding mexicanization. Finally, to make a contrast of the Tarahumara situation, it presents the case of migration to Juarez city.
\end{abstract}

Keywords: Mexico, tarahumara, liberties, acculturation, resilience 
Les Indiens raramuris (tarahumaras du Mexique) et les libertés

\section{Résumé}

Pour commencer, cet article tente d'appréhender la notion de liberté chez les Indiens tarahumaras du Mexique selon leur propre conception. Ce préliminaire établi, il fait une synthèse, depuis la colonisation jusqu'à nos jours, des libertés perdues, puis préservées, acquises et reconquises. Ensuite, à partir des résultats des recherches sur le terrain adressées à des Tarahumaras migrants vers Ciudad Cuauhtémoc, il réalise le bilan de ces libertés dans l'actualité; avant de conclure en proposant des perspectives et des solutions qui s'offrent aux différents acteurs : sociologues, anthropologues, chercheurs ainsi qu'aux membres de cette ethnie. Des annexes complètent l'historiographie de la mexicanisation, exposent les conséquences de la scolarisation, avancent des points de vue d'anthropologues au sujet de la mexicanisation, rappellent les importations technologiques et, par rapport aux migrations, présente, en contrepoint, le cas de Ciudad Juarez.

Mots-clés: Mexique, Tarahumaras, libertés, acculturation, résilience 


\section{Introducción}

Como requisito previo a este estudio, definiremos lo que puede ser o representar la noción de libertad y en qué consisten las «libertades» para la etnia rarámuri - ¿existen este concepto y esta palabra en su idioma?- en la Sierra Tarahumara, que ocupa una zona que cubre un cuarto de la superficie del estado de Chihuahua, o sea unos $65000 \mathrm{~km}^{2}$, al noroeste de México. A continuación, desde un punto de vista científico, repasaremos esas libertades intrínsecas perdidas, preservadas o reconquistadas en el transcurso de su historia, desde la colonización hasta hoy en día. Además, recurriremos a testimonios y percepciones propias de miembros de esta comunidad, accesibles a la «civilización moderna», no atrincherados en zonas remotas y abiertos a la comunicación: ¿cómo perciben lo que podríamos considerar como un modus vivendi entre ellos y los mestizos?; ¿cuál es el sentimiento que experimentan?, ¿tienen expectativas?, y, sobre todo, ¿han sido o se sienten expoliados o enajenados? y ¿Están en conflicto, en oposición contra los mestizos?

Para llevar a cabo una investigación en terreno, recurrimos a un cuestionario dirigido a unos tarahumaras que visitan o viven en Ciudad Cuauhtémoc ${ }^{\mathrm{I}}$. Este fenómeno de emigración temporal o duradera ya es una señal del cambio de sus costumbres e idiosincrasia ancestral. ¿Pero esto presume de una pérdida o de una adquisición de libertad(es)?

\section{La noción de libertad en los tarahumaras ${ }^{2}$}

En primer lugar, este artículo ofrece una mirada sobre una etnia que constaba de 85 oI8 miembros en 20IO (INEGI, 20IO), entre los cuales una gran mayoría vive de manera nómada o seminómada entre las altas planicies y el fondo de los cañones del estado de Chihuahua, muy a 
menudo independientemente de la civilización llamada «moderna», muy libremente. En segundo lugar, alejados de los núcleos urbanos, evitando los contactos con los chabochis ${ }^{3}$, es muy difícil acercarse y comunicar con ellos. El Dr. Carlos Maldonado Ortíz ${ }^{4}$ convivió y trabajó con aborígenes y mestizos por la Sierra Tarahumara, periódicamente, durante dieciséis años. Ha publicado un libro de primera importancia que aporta numerosos testimonios de su vivencia.

Es interesante notar que el vocablo «libertad» no figura en los diccionarios consultados 5 . De hecho, este concepto de libertad, inherente a la comunidad tarahumara ha de ser percibido de diferentes maneras pues se trata de una etnia plural, compuesta de una muy gran diversidad de subgrupos heterogéneos, en posible comunicación por la zona geográfica de su hábitat. Entre ellos, existen muy grandes diferencias lingüísticas (fonéticas, lexicales y gramaticales) que pueden hacer sus conversaciones ininteligibles. La variedad de diferencias toca también la indumentaria, así como el grado de aculturación. El término basorowa designa “ 'la libertad de movimiento', es decir la libertad más enajenable según ellos. Es el valor supremo de toda moral por la cual siempre han luchado" (Coutarel, 1996, p. I68) ${ }^{6}$.

Es de notar también que el niño tarahumara, desde que es capaz de caminar, se ve casi abandonado a su suerte: empieza a explorar el mundo a su alrededor y, por consiguiente, está relacionado con la naturaleza de modo autónomo y libre. Pero esa libertad sólo se le da para que vaya aprendiendo por él mismo a conocer y respetar mejor el medio en el que vive y es limitada, en cuanto lo puede, por la obligación de sostener a su familia en los quehaceres. De manera que el concepto de libertad es tan natural e inherente a ellos que nacen y viven libres.

Y, con respecto a nosotros, occidentales, ¿es posible pensar que esta etnia sea libre? Basándose en McDougall (2012), lo fue antes de la 
llegada de los españoles. En su origen, son hombres pacíficos, desinteresados y que viven sin sistema monetario, leales, solidarios, trabajadores y honrados. Su vida en comunidad ha mostrado todas sus cualidades y, consecuentemente, son libres de casi todos los males de muchas civilizaciones; no dependen de nadie (excepto de la ayuda mutua natural en sus faenas agrícolas) y son la encarnación de un pueblo libre. Sin embargo, no han podido permanecer así y han perdido, con el paso de los años, muchas libertades.

\section{Las libertades alienadas o en retroceso}

Hacia I63I, el descubrimiento de importantes yacimientos de plata en Parral, Chihuahua, provocó un flujo migratorio de buscadores y mineros, luego de agricultores y ganaderos españoles que se apropiaron los mejores terrenos agrícolas. La primera libertad perdida es, pues, la privación de sus tierras arables igual que el agua para regar los campos, fenómeno que perdura aún hoy en día, como lo subraya Carlos Maldonado Ortiz:

Para el indígena este era simplemente un episodio más en su inacabable búsqueda de nuevas áreas de cultivo [...] sufriendo desde entonces el despojo constante de sus mejores tierras, que lo ha orillado a ocupar las zonas más agrestes de las barrancas. Aún en la actualidad, los mestizos les disputan los pocos terrenos planos que poseen apoyándose en ciertas autoridades cuya mentalidad racista es a veces sutil, pero siempre presente e implacable (2009, pp. 7-8).

Eso se debe al crecimiento de las localidades mestizas que ha obligado a ciertas familias a sedentarizarse. Por otra parte, los rebaños españoles se extendían frecuentemente por las tierras cultivadas y de pasto 
poseídas por los indígenas. A esto se añaden parcelas escarpadas (las cuales, a menudo desbrozadas, vienen a ser erosionadas e infértiles), la escasez de agua, la naturaleza pedregosa de las tierras y la pobreza de los suelos. Por si fuera poco, tienen poco rebaño, por lo tanto, disponen de escasos abonos naturales; la productividad de los cultivos es baja y las cosechas insuficientes. La consecuencia ha sido la desnutrición y hambrunas casi endémicas, esencialmente en invierno.

La segunda libertad alterada, la incitación forzada a su sedentarización, en otras tierras que las suyas, empezó con la llegada de los misioneros jesuitas que, como en toda la Nueva España, establecieron el sistema de reducciones $^{7}$, premisas de las misiones, con el objetivo de evangelizarlos mejor y controlarlos administrativamente.

En consecuencia, desde I639, con la creación de las misiones tarahumaras por los jesuitas, acarreando su evangelización, su libertad de creencias y de ritos cultuales ha sido alienada y, por tanto, sus tradiciones y cultura. Jérôme Coutarel no vacila en hablar de "conquista espiritual” (I996, p. II2) ${ }^{8}$ a la cual fueron sometidos. Si había una resistencia, los misioneros (luego los colonos) no se andaban con rodeos en recurrir al ejército y a la fuerza: los latigazos, las casas quemadas, los cultivos destruidos, las mujeres y los niños tomados como rehenes no escaseaban como lo evidencia Maldonado (2009):

Son aterradores algunos relatos coloniales; por rehusarse a aceptar la nueva religión, se acusaba a los indios de herejía o de ser hechiceros enviados por el Diablo, condenándolos a la horca. Muchos indígenas prefirieron huir a las montañas antes que renunciar a costumbres ancestrales como la poligamia, las tesgüinadas ${ }^{9}$, la idolatría y la vida en el monte (p. 23). 
La institución del trabajo obligatorio debido a la falta de mano de obra española para las minas y la agricultura pronto se tornó en esclavitud. McDougall da una imagen peor de lo que fue la colonización para ellos recopilando, con propósitos virulentos, hechos que les quitaron la libertad incluyendo la de vivir:

La última vez que los tarahumaras se abrieron a ellos [a los extranjeros], les avasallaron y colocaron sus cabezas en puntas de tres metros de alto. Los españoles ávidos de plata se adueñaron de sus tierras y descabezaron a sus jefes.

Los rarámuris eran acorralados como caballos salvajes y reducidos a la esclavitud en minas, escribe un cronista de la época. Todos los que se resistían, dice, se volvían los principales protagonistas de verdaderas escenas de terror. Antes de ser ejecutados, los tarahumaras capturados eran sometidos a un interrogatorio. He aquí todo lo que sus descendientes recordaban de los extranjeros (p. 48$)^{1 \mathrm{D}}$.

La importación de enfermedades y epidemias desconocidas por los autóctonos provocó una tasa de mortalidad muy elevada e incitó más a los indígenas a abandonar las misiones.

Las rebeldías violentas que implicaban a veces a miles de hombres y las represiones feroces españolas que siguieron acabaron con su resistencia pacífica y su aparente sumisión administrativa y religiosa.

A fin de escapar de todas esas obligaciones y malos tratos, los tarahumaras tuvieron que exiliarse primero hacia la Tarahumara Baja o Tarahumara Antigua, entre Parral y Chihuahua, luego hacia el noroeste de esta primera zona, en un sector contiguo, en la Sierra, la Tarahumara Alta o Tarahumara Nueva donde, a su vez, ocuparon el lugar de otras etnias que fueron asimiladas o desaparecieron ${ }^{\mathrm{II}}$. 
En ese nuevo hábitat, como lo pone de relieve Jérôme Coutarel, se encontraron confrontados "a la dura realidad de la Tarahumara [...] maltrecha por la miseria [y su tribu se vio] diezmada por la enfermedad [pues están] privados de un medio natural fértil y son víctimas de los caprichos del clima” (1996, p. IOI). Viviendo en la pobreza, muy someramente vestidos, padecen del frío glacial que paraliza sus actividades agrícolas y acarrea enfermedades, tales que la disentería, la neumonía y epidemias (malaria, viruela...), estas, junto con las condiciones de higiene lamentables, a menudo son mortales. Coutarel va hasta calificar de "malsanas y execrables" (p. I06) las condiciones en las cuales viven. Esa miseria es sin duda alguna la mayor alienación para este pueblo.

Asimismo, se han visto obligados a recurrir a las ayudas médicas del Estado, lo cual ha acrecentado su aculturación que va creciendo tanto más cuanto que la infraestructura establecida por el Estado provoca un éxodo de las montañas hacia las tierras bajas y, poco a poco, la medicina moderna supera el chamanismo ancestral. Y eso tiene aún más un impacto ya que las prácticas mágicas y religiosas tradicionales siempre han desempeñado un papel relevante para ellos.

Desde la llegada de los españoles, la colonización de los territorios por los hombres blancos y mestizos ha empezado a modificar profundamente el medio ecológico, principalmente con la caza de los animales salvajes, la cría de animales domésticos (los cerdos criados en libertad), el saqueo de las riquezas forestales (para la construcción de edificios y obtención de combustible) y minerales, lo que ha conducido a una deforestación abusiva en el estado y a la contaminación de los ríos debido a la liberación de sustancias químicas empleadas en las minas. La llegada del ferrocarril a partir de finales del siglo XIX ha abierto un acceso a más colonos y turistas. No obstante, durante nuestros viajes ${ }^{\text {I2 }}$ 
por la Sierra, no sentimos ese impacto tan negativo; al contrario, la región nos pareció relativamente preservada, de la misma manera dotada de infraestructuras pero que no desfiguran el paisaje y, por lo visto, no provocan la degradación de este marco de vida.

En cambio, cabe señalar una modificación significativa de su modo de vivir: la mexicanización ${ }^{13}$. A partir del siglo XVIII y hasta los años I930, grupos mestizos se instalaron cerca de los ríos Papigochi y Conchos y comenzaron a establecer relaciones comerciales, aculturando a tarahumaras que entraron en el sistema de valores de los mexicanos, a saber, el uso del peso. Bajo la colonización, el objetivo de las reformas políticas de los Borbones apuntaba a incorporar al indio por su total asimilación a la sociedad occidental, adueñándose y explotando las tierras al mismo tiempo, hasta el siglo XX en que el gobierno, mediante la gestión del Instituto Nacional Indigenista, orientó su política hacia la integración intercultural de los indios por la educación, el desarrollo agrícola, la creación de una red de infraestructuras y de salud así como la administración de la justicia.

La cultura ancestral del peyote por ciertos miembros les fue reducida también, casi suprimida, pues el consumo de la raíz de este hongo les hacía desobedientes a los mestizos, según las autoridades de México, como lo recalcó Antonin Artaud (2004). Por fin, una de las llagas que más les afectan es la cultura y el tráfico de drogas, esencialmente en la parte sur de la Sierra. Efectivamente, los narcotraficantes han creado terracerías clandestinas ${ }^{\mathrm{I} 4}$ recorridas por patrullas de policía y del ejército (inclusive aéreas). Otra perturbación que hay que notar es la explotación por los chutameros (narcos) de los indios, forzándoles a servir de guías, e incluso de mulas, cometiendo abusos y violencia.

La enseñanza escolar ha sido impartida a los indios por la Secretaría de Educación Pública, desde 1922, en el marco de la reforma educativa 
(segunda parte de la mexicanización), y, bajo la coordinación del Instituto Nacional Indigenista que ha construido, a partir de 1927, escuelas rurales, llamadas después Misiones Culturales, hasta I950; luego albergues-escuelas.

Ese fenómeno de aculturación se ha desarrollado con la construcción de una red ferroviaria y carretera del gobierno que une los estados de Chihuahua, Sonora y Sinaloa.

En el transcurso de la historia, este pueblo ha sido víctima de abusos, como lo argumenta Francisco M. Plancarte:

[...] son chabochis, gente extraña que vino a meterse en su territorio y que le acarrea molestias y perjuicios incontables; ladrones que les han arrebatado sus mejores tierras, que abusan de sus mujeres, que les roban su ganado y que, en el mejor de los casos, realizan con ellos tratos y transacciones comerciales en que mañosamente siempre les quitan lo más para darles lo menos (1954, p. 35).

Desde comienzos del siglo XXI, con el aumento de los precios de los metales como el oro ${ }^{15}$, la plata, el cobre y el plomo, empresas mexicanas y en particular canadienses han reabierto varios viejos centros mineros abandonados. Sariego (2009) califica de "alto grado de penetración del capital canadiense en la Sierra de Chihuahua, un fenómeno sin precedente en la historia" (p. 5). A partir de mediados del 20I2, algunas empresas han disminuido su actividad o se han retirado, dejando daños medioambientales sin ningún beneficio para los autóctonos. El auge del turismo «espectacular» o «de aventura», él tampoco, no les ha beneficiado ni en términos de empleos ni en ingresos ya que los capitales son o bien privados o bien de Estado, así pues, fuera del alcance de la economía indígena. En contraposición, unos proyectos 
mucho más modestos, como en San Ignacio de Arareko o Cusárare, han permitido ayudar a la gente. La pobreza sigue siendo el principal infortunio que ninguna política ni programa ha logrado remediar. El narcotráfico y la violencia organizada han venido a empeorar la situación, sobre todo desde 2008. Por su extensión (consta de 23 municipios en $68344 \mathrm{~km}^{2}$, según datos del Instituto Nacional Indigenista) $)^{16}$, su alejamiento, su aislamiento, su relieve muy escarpado, la influencia de los cárteles de la droga, esta región parece haber vuelto a ser abandonada. Por añadidura, en distintos grados, están aculturados y algunos incluso usan teléfonos celulares o radios. Algunos casos de toxicomanía, de alcoholismo y hasta de homicidios no escasean. ${ }^{17}$

Por causa de las condiciones de vida muy difíciles en la Sierra y ante todo el hambre, hay quienes están obligados a emigrar temporalmente ora hacia las plantaciones de verduras de los valles fértiles de Sinaloa o para Ciudad Cuauhtémoc, Chihuahua y Ciudad Juárez, ora para trabajar a destajo como jornalero o bien con el fin de pedir limosna por las calles.

\section{Las libertades preservadas, adquiridas y reconquistadas}

\section{Las libertades preservadas}

Por el hecho de que, desde hace siglos, su hábitat ha venido a situarse en lugares cada vez más remotos, en su conjunto, no están sometidos a presiones externas importantes. Y, por eso, podemos pensar que la cuestión de las libertades no es fundamental a priori para ellos en esos lugares aislados. Por cierto, han perdido su libertad de vivir en las dos llanuras centrales del estado de Chihuahua $^{\mathrm{I} 8}$, pero han vuelto a encontrar esa forma de libertad por esa inmensa zona montañosa donde han establecido su domicilio y viven más libremente que en 
presencia de los españoles o mestizos, siguiendo sus usos y costumbres ancestrales en su gran mayoría. Han conservado, pues, su proprio modo de vida. Empero, las variaciones climáticas debido a las estaciones y al relieve les han condicionado al seminomadismo al cual, en definitiva, se han adaptado bien. Si su modo de vida ha permanecido casi idéntico: continúan viviendo de la agricultura de subsistencia, cultivando maíz, frijoles y calabazas, en complemento de la caza ${ }^{19}$, la pesca y la recolección de frutas silvestres. Han podido conservar también su ropa tradicional igual que su idioma.

A nivel espiritual, habida cuenta de la necesidad de recurrir a catequistas tarahumaras (por falta de misionarios en suficiente número) para transmitir el cristianismo, la doctrina cristiana pura no ha sido enseñada con exactitud, provocando un sincretismo religioso "extraordinario" (Maldonado, 2009, p. 28) y manteniendo una sobrevivencia de las creencias y de los ritos tradicionales; tanto más cuanto que esta confesión no ha podido ser asimilada por los indígenas que la han entendido a su manera, transformándola y adaptándola en función de su cosmovisión. La manifestación más patente de la aceptación del cristianismo, si bien sincrética, se traduce en las fiestas de la Iglesia de primera importancia en la vida religiosa, social y cultural de este pueblo.

Entre los elementos del «movimiento de defensa de su patrimonio cultural», J. Coutarel incluye su "medicina tradicional basada en creencias y técnicas ancestrales" (Coutarel, I996, p. I06), la cultura y el uso del peyote, la absorción de tesgüisno y el chamanismo. 


\section{Las libertades adquiridas}

Los aportes tecnológicos de origen europeo han mejorado su vida cotidiana en muchos aspectos. En efecto, los jesuitas les legaron adelantos en el plano agrícola, al enseñarles cultivos y técnicas agrícolas. Despecho a esos numerosos avances, su sistema agrícola ha evolucionado muy poco desde el siglo XVII y sigue siendo a menudo arcaico e insuficiente.

Los medicamentos traídos y los cuidados sanitarios proporcionados por enfermeros y médicos (del INI), efectuando frecuentemente su servicio social, muy jóvenes e inexperimentados, les han permitido curarse mejor frente a las nuevas enfermedades importadas por los colonos, guardando al mismo tiempo la libertad de ser o no ser sanado por la medicina moderna y/o los remedios y las plantas de los curanderos de su comunidad. Las mujeres que lo desean pueden tomar la píldora anticonceptiva, otro adelanto que les da una libertad más. Respondiendo a las demandas de los jefes locales, el Estado mandó construir dispensarios y clínicas.

Los misioneros jesuitas han instaurado un nuevo sistema de mando que ha perdurado hasta nuestros días. Este se compone de un gobernador general y dos gobernadores secundarios que imparten justicia, de acuerdo con la comunidad tarahumara y las autoridades mestizas. Parece que este nuevo sistema representa para ellos la adquisición de una libertad, a saber, que ahí donde no había autoridad competente, la presencia y el rol de los gobernadores son apreciados. Por otra parte, en algunos lugares, la educación católica les ha permitido reunirse regularmente, lo cual ha contribuido a su socialización, así como a la mejora de sus condiciones de vida. 
Amén de todas esas adquisiciones, el ferrocarril ha hecho evolucionar sensiblemente parte de la sociedad tarahumara, o sea los indios que han querido sacar provecho del mundo moderno. La construcción de la vía férrea y de su infraestructura, entre I940 y I96I, dio empleos a miles de autóctonos - hasta 9000 - de los cuales un gran número de indígenas, sin que tuviesen que abandonar la Sierra. Por otro lado, ese eje de comunicación no ha desestructurado a la sociedad tarahumara, pero ha hecho posible su adaptación a la modernidad. Recordemos que estos autóctonos viven por zonas, en su mayor parte, muy distanciadas de la vía férrea y que su carácter y modo de vida atañe, antes que nada, al aislamiento deliberado, su «política» siendo la de la resistencia a la civilización occidental moderna.

\section{Las libertades reconquistadas}

Primer hecho notable, en 1767 , acusados de enriquecimiento y apoderamiento, los jesuitas fueron expulsados de las posesiones españolas. Los franciscanos tomaron el relevo, pero, por falta de medios suficientes, no pudieron llevar a cabo su obra, lo que acarreó la vuelta de los indígenas a sus rancherías; el sistema de reducciones fue abolido mientras que el legado jesuita fue conservado.

Segundo hecho histórico, en I82I, con la Independencia de México, los misioneros españoles fueron expulsados del país y la iglesia perdió

\section{4 muchos bienes.}

Entre I856 y I863, bajo las presidencias de Ignacio Comonfort y Benito Juárez, les Leyes de Reforma instauraron la separación de la Iglesia y del Estado, suprimieron las órdenes religiosas en México y establecieron la desamortización de sus bienes. Estos hechos marcaron 
un hito en la reconquista de sus valores, como lo pone de manifiesto Maldonado (2009): "Estos acontecimientos liberaron a los indígenas del dominio de los centros misionales, favoreciendo su autodeterminación, y fueron uno de los principales factores que les permitieron conservar sus ancestrales rasgos culturales" (p. 32).

En I900, los jesuitas pudieron volver a la Tarahumara hasta la Revolución durante la cual fueron deportados a los Estados Unidos por Francisco Villa, antes de retornar en los años de 1920.

Un balance muy pormenorizado, en cinco cuadros recapitulativos, sobre los elementos desaparecidos, persistentes, deteriorados de la cultura tarahumara, completado por los principales aportes exteriores, ha sido establecido por Bennett y Zingg, y han sido retomados por Sariego (2009) que nota así la supervivencia de los grandes rasgos de esta civilización: "los antiguos rasgos persistentes son cuantitativa y cualitativamente predominantes sobre aquellos otros que han desaparecido, han sido asimilados de fuera o se han combinado con otros externos" (p. 77) ${ }^{20}$. Esos estadounidenses adelantan su capacidad de conservar "tenazmente su antigua cultura [y hasta se asombran] que no se hayan mexicanizado más [...]" (Bennett y Zingg, I986, p. 568); van hasta mostrar que, por supuesto, son capaces de hacerse suyos elementos exteriores, pero también de modificarlos, retocarlos a su manera, de tal modo que su cultura no se halle profundamente afectada, como lo hacen constar: "hay una delgada capa superficial de elementos españoles e indios, que es posible separar, con bastante seguridad o certidumbre, de los elementos prehispánicos (Bennett y Zingg, I986, p. 575).

Hoy en día, existe en Creel, una oficina de Derechos Humanos, no oficial, acompañada de tres centros culturales, gestionados por los padres jesuitas ${ }^{2 I}$. Además, miembros del INI se dedican 
particularmente al servicio social en actividades como la construcción de escuelas, talleres y hospitales, lo cual constituye avances sociales y sanitarios que brindan más libertades a la población local.

Por ende, nos parece pertinente orientar un cuestionario, encaminado a la implementación de una encuesta de rarámuris, para los que podríamos calificar de desarraigados, obligados a abandonar su comunidad y entrar en contacto con la civilización moderna principalmente porque no logran vivir decentemente, es decir producir sus cultivos alimentarios y nutrirse lo suficiente.

En esta óptica, podemos preguntarnos si van al contacto de los mestizos con la esperanza también de adquirir libertades y, en este caso, ¿cuáles? Si están sometidos a una aculturación voluntaria o involuntaria, y -una vez aculturados- ¿han llegado a ser más libres que antes o se sienten alienados? este es el lugar central de esta problemática.

\section{Resultados y conclusiones de las encuestas de campo}

Estas encuestas fueron aplicadas en abril de $2017^{22}$, a 45 rarámuris migrantes de la Sierra Tarahumara a Ciudad Cuauhtémoc, Chihuahua. Se trata de $\mathbf{3} 3$ hombres y 32 mujeres, de I2 a 87 años y de quienes la mitad -aproximadamente- han migrado por primera vez.

\section{Las libertades en ocaso}

Tanto para los hombres (el 77\%) como para las mujeres (el 67\%), la causa principal de migración de la Sierra hacia esa ciudad es la búsqueda de un empleo. Esto confirma el hecho de que hayan llegado a ser 
dependientes del sistema económico occidental moderno: necesitan ganar dinero para comprar y consumir bienes y productos.

La gran mayoría de los hombres (un $77 \%$ ) estiman no haber perdido libertades al vivir en la ciudad, así como para las mujeres (un $72 \%$ ). Sin embargo, un $53 \%$ de los hombres y un $72 \%$ de las mujeres sienten como una obligación la migración o la estadía en la ciudad; lo cual da un total de más del $66 \%$. Así pues, podemos considerar este cambio de lugar de vida como una pérdida de libertad. Pese a esto, el $54 \%$ de los hombres tienen el sentimiento de ser libres en la ciudad, está correspondiendo a sus expectativas (ofertas de empleo en primer lugar y nuevos hábitos) y esa cifra es superior con creces para las mujeres puesto que alcanza el $75 \%$. Entonces, si la migración es obligada, el modus vivendi ciudadano les conviene a la gran mayoría (cerca del $69 \%$ en total). En su conjunto, ahí viven bien puesto que pueden trabajar y el marco de vida de esta pequeña ciudad provincial les cae bien. Amén del trabajo, punto principal, disponen igualmente de más productos (acceso a la comida, ropa, calzados), bienes y servicios (sobre todo escolares y médicos), de oportunidades de ocio y diversiones (televisión, radio, cine, restaurantes, parques). Algunos incluso llegan a decir: "vivir bien y estar bien", "estar a gusto" (esta expresión es recurrente). Las quejas son la inseguridad y los gastos inherentes a la vida urbana.

Pero, cuando se les interroga sobre su sentimiento de ser libre o de gozar de una mayor libertad por la Sierra, indiscutiblemente, hombres y mujeres contestan casi por unanimidad con la afirmativa (un $77 \%$ para los hombres y un $90 \%$ para las mujeres, o sea casi el $87 \%$ para el conjunto). Las razones, si bien expresadas muy diversamente, tienden esencialmente hacia el que se trata de su lugar de nacimiento y de los primeros años de su existencia; la calidad de vida (más sana, más segura, la naturaleza, la quietud, el espacio más vasto y las libertades en general). 


\section{Las libertades preservadas o en adquisición}

A propósito de sus relaciones con los mestizos, los hombres afirman unánimemente que son buenas y se sienten en seguridad, aunque, profundizando el cuestionario, tres casos vienen a minorar este resultado: los que están "en conflictos”, "en problemas con los policías" y el sentimiento de estar "excluidos". En cuanto a las mujeres, más del $84 \%$ abundan en este sentido. Esta tasa inferior es, sin duda, debida a su condición femenina e indígena a pesar de que el $87 \%$ dice sentirse en seguridad. Aun cuando, conviene señalar que más del 15\% declaran ser o haber sido explotadas o abusadas y el $6 \%$ desposeídas o robadas, sólo para mencionar los problemas más graves.

Lo que esperan de los mestizos, es más que nada buenos sentimientos, una mayor igualdad o, por lo menos, respeto. Esto se traduce por un $46 \%$ de opiniones masculinas en este sentido y un $40 \%$ de las femeninas. Esperan de igual modo seguir siendo apoyados, ayudados, en particular por oportunidades de empleos y un mejor acceso a los servicios médicos.

Para ir más lejos en sus opiniones, en lo que concierne a los matrimonios exogámicos, están muy divididos: alrededor de un $54 \%$ de los hombres son favorables en contra de tan sólo un $40 \%$ de las mujeres. En efecto, los hombres parecen ser más abiertos, dispuestos a ir hacia el otro (los no tarahumara), listos para compartir sus sentimientos, un conocimiento mutuo, la igualdad entre hombres y mujeres mientras

178 que las mujeres, mucho más tradicionalistas oponen las diferencias entre las costumbres y las culturas mayormente.

Sobre los vínculos y las relaciones que mantienen con sus familias que han permanecido en la Sierra, prácticamente todos (salvo una excepción para los hombres y otra para las mujeres) declaran 
mantenerlas, llevarse (muy) bien e incluso visitarlos regularmente. Podemos concluir que, por lo pronto, no se han separado de sus orígenes, de su familia y continúan reconociendo su cultura original.

A final de cuentas, podemos deducir que, frente a esa dura realidad en la Sierra, teniendo muchas dificultades para subsistir, se ven obligados a tener un empleo remunerado y, para ello, ir a la ciudad. Ya han pasado a ser víctimas de esa alienación común al conjunto de la humanidad: la dependencia del modo de vida moderna que, en su caso, fundamentalmente les obliga. Mas, esos migrantes, en su mayor parte, han mostrado una gran capacidad de adaptación e integración a su nueva vida, sin grandes sufrimientos, haciendo gala de pragmatismo y eficacia, conservando al mismo tiempo valores humanos tales como la dignidad adquirida por el trabajo, el respeto, las buenas relaciones, hasta la amistad y el amor. Por ello, habiendo logrado hacer abstracción de esa alienación inherente a la sociedad moderna y de su desarraigo forzado, como muchos otros migrantes, las tres cuartas partes de ellos no se sienten privados de libertades, pese a que, en el fondo de ellos mismos, subsiste lo que podríamos llamar cierta forma de nostalgia de su vida anterior para más del $86 \%$ de las personas interrogadas. Mejor aún, lejos de ser infelices de su suerte, han logrado seguir o volver a empezar una vida y sacar ventajas, de ahí sus sentimientos de estar a gusto y de apreciar encontrarse en la ciudad. Estos buenos resultados se confirman asimismo en los aspectos relacionales intra y extraétnicos dado que han guardado, y con frecuencia esperan a cambio, los valores del altruismo, la solidaridad y el humanismo propios de esta etnia. Y, lo que es más, no se han dejado pervertir por las angustias de vida ciudadana, al contrario, dan la impresión de intentar preservarse de eso, aunque tengan que ensimismarse un poco (reduciendo, por ejemplo, sus movimientos, especialmente por las personas que se sienten inseguras). Por fin, el número relativamente elevado de 
tarahumara migrantes hacia las ciudades muestra no sólo la situación muy precaria en la que viven originalmente sino también su preferencia (unos no han vacilado en decirlo) por la ciudad. Algunos se han acostumbrado tanto, llegando hasta la aculturación, que viven y reaccionan como mestizos en su pequeña vida tranquila y confortable (notemos que el adjetivo ha aparecido repetidas veces). Entonces parecería que sus condiciones de vida se hayan mejorado.

En conclusión, en Ciudad Cuauhtémoc, las cosas parecen transcurrir bien para ellos, posiblemente gracias al hecho de que se trata de una pequeña ciudad ${ }^{23}$, que se sitúa cerca de la Sierra y que su desarrollo se ha hecho a partir de la llegada de los inmigrantes menonitas de Canadá en I92I-I922. En cambio, para dar otro ejemplo de ciudad de destino, en Ciudad Juárez, su acogida y situación son todo lo contrario.

A continuación, procede ahondar el concepto de la mexicanización aplicado a esta área, haciendo una síntesis histórica hasta la actualidad; dar a conocer los resultados de la escolarización así como los puntos de vista de antropólogos acerca de la mexicanización; poner de manifiesto las importaciones tecnológicas que representan un avance de primer orden; y acabar contraponiendo el caso de Ciudad Juárez al de Ciudad Cuauhtémoc en lo que atañe a la adaptación de los migrantes en el medio urbano.

\section{La mexicanización}

La política de primera colonización mestiza de apropiación de las tierras y de explotación de los minerales es llamada "política del mestizaje" (Sariego, 2009, p. 197) ${ }^{24}$ de la Sierra. Permitía sentar el poder e impedir las revueltas multiétnicas; esto acarreó la transformación de 
la región y una pérdida notable de libertades para los autóctonos, como lo pone en primer plano Sariego: "El territorio [...] se convirtió en un espacio de litigio cultural entre indios y mestizos” (2009, p. 198). Ella ha tenido un éxito muy limitado a los centros mineros, los indios, habiéndose dispersado, siguiendo su modo de vida ancestral. En el siglo XIX, esa política fue sostenida por las leyes de I825, I856 y I859. Se ha intensificado a partir de la realización de la reforme agraria y de la educación indígena, entre 1920 y 1952, mayoritariamente a favor de los mestizos que ya se habían apropiado parcelas indígenas y se instalaron en los ejidos recién atribuidos. El principio descansaba en que "el indio y su cultura son incompatibles con un proyecto de nación" (Sariego, 2009, p. 198) y que había que erradicar el modo de vida indígena. Esa política incluía una repoblación territorial (entre 1767 y I827, se estima que el número de personas pasó de 600 a 6000 en los valles orientales y el macizo centro-occidental) unido a la desintegración de los pueblos de misión franciscana. Posteriormente, el gobierno, a través de la gestión del Instituto Nacional Indigenista, creado por la ley votada el io de noviembre de 1948, consideró las regiones aisladas y subdesarrolladas de México como "refugios" y la palabra clave fue la integración intercultural de los indios por la educación, el desarrollo agrícola, la creación de una red de infraestructura y de salud, así como la administración de la justicia. Este "modelo" teórico para el proceso de aculturación, válido para Chiapas, era inadaptado a la región serrana de Chihuahua donde no había cabeceras municipales en las que se pudieran instalar las sedes de los Centros Coordinadores del INI, sino rancherías dispersas y aisladas junto a antiguos centros mineros desafectados y poco poblados. La construcción del tramo de $248 \mathrm{~km}$ de la línea ferroviaria Chihuahua al Pacífico, por la Sierra, entre 1940 y I96I, conllevó la contratación ${ }^{25}$ y la subsistencia de numerosos indígenas - unos 25000 sobre 65000 - como obreros y tuvo un impacto relativamente importante en el fenómeno de aculturación ${ }^{26}$ en muy 
buenas condiciones y relaciones humanas de gran calidad. Desde la puesta en servicio de la línea de este ferrocarril en su totalidad, en 1962, las mujeres tarahumaras, muchas veces con sus hijos, las que han escogido adaptarse al turismo y sacar un mísero salario con la confección y la venta de objetos artesanales en los andenes, se han visto en competencia con los comerciantes que les han comprado toda su existencia a un precio irrisorio para revenderlo en sus tiendas o en tianguis, con más ganancias. Para colmo de esta competencia desleal, algunos mestizos han mandado fabricar copias o imitaciones de los productos indígenas y los venden prácticamente al lado de los puestos de venta de los tarahumaras. Estos han elegido abandonar la agricultura y la ganadería para dedicarse al comercio, sedentarizándose. Así que han llegado a ser dependientes de la economía mexicana moderna: si quieren comprar productos necesarios, están obligados a vender su artesanía. Las ciudades y los pueblos más afectados son Creel, Bocoyna, Nonoava, Batopilas. El análisis de Coutarel (1996) muestra igualmente, sin exageración, una "automexicanización", una "sociedad de consumo" y concluye sobre un "trastorno de ciertos valores de la cultura tarahumara" (pp. I23-I25) con consecuencias lamentables:

Las consecuencias de esta mexicanización son de una lógica dramática: desigualdades sociales en el seno de la tribu, empeoramiento de la miseria y de la desnutrición, debilitamiento del organismo, vulnerabilidad aumentada a las enfermedades, aparición de una forma de delincuencia. Dicho de otra manera, el "círculo vicioso" del subdesarrollo (p. I26). 


\section{Los resultados de la escolarización}

El resultado logrado -la hispanización por el idioma y la cultura, con la finalidad de desarrollar la región y mejorar el nivel de vida de los autóctonos- no ha estado, tampoco en este caso, a la altura de las expectativas ni de los intereses en juego. Esta cuestión puede contemplarse bajo dos ángulos opuestos. A primera vista, puede parecer legítimamente como la adquisición de una libertad, el acceso a la educación escolar como en el resto del país. En verdad, los padres dan su acuerdo para mandar a sus hijos a estudiar porque están atendidos, nutridos y criados. Esta obligación escolar está en contradicción con la tradición apropiada que les permitía adquirir el conocimiento de su medio ambiente y les preparaba a vivir mejor en él. Maldonado expresa su crítica sin equívocos sobre este tema:

Al querer imponerle un estilo de vida y un idioma ajenos, se atenta contra su integridad natural pues se afecta negativamente la mentalidad infantil, dañando la estructura fundamental de esta sociedad milenaria. El niño es víctima de un silencioso despojo cultural que no le reditúa nada a cambio [...] (Maldonado, 2009, p. I42).

Además, la escolarización, asociada a los servicios conducidos en español por los jesuitas, junto al comercio con los mercaderes mexicanos, es un factor de la aceleración de la aculturación lingüística, inclusive de vestimenta. Todo eso influencia sobre todo a los jóvenes que pueden tomar como modelo lo que se les enseña y, a corto plazo, esa ladinización puede representar una amenaza de desarraigo o deculturación del indígena. Coutarel ha escrito al respecto: "la Tarahumara está hoy sometida a los mecanismos de une aculturación galopante" (I996, p. 33). Otro hecho notable: muy pocos estudiantes indios en las grandes ciudades desean volver a la Sierra una vez 
acabados sus estudios. Y estos pueden tener un efecto devastador a nivel lingüístico: el olvido o la pérdida de su lengua vernácula, como lo deplora el poeta e investigador chihuahuense Enrique Servín: "las escuelas, como lo han dicho los compañeros rarámuris en muchas ocasiones, son fábricas de chabochis; los niños entran monolingües en tarahumara y salen monolingües en castellano" (Crece en Chihuahua la generación..., 20I7, s/p).”

\section{Los puntos de vista de antropólogos acerca de la mexicanización}

A este respecto, Carlos Basauri, el primer antropólogo mexicano que condujo un estudio de campo sobre esta etnia, respaldaba esta tesis a finales de la década de 1920, que Sariego (2009) vincula a la teoría del primitivismo marcado por un pesimismo, debido al fracaso de la política indigenista encaminada a la educación por las escuelas jesuitas confrontada a las reticencias de los indios. Esta constatación ha sido confirmada por los estudios etnográficos de dos antropólogos estadounidenses: Robert M. Zingg, de la Universidad de Chicago, Wendell C. Bennett, de Yale. Así, para ellos, no hubo aculturación ni cambio social significativo. La visión más reciente de C. Maldonado, atestigua esa resistencia étnica: "se conserva la independencia individual, se satisfacen las necesidades de comunicación social. Las familias llevan una existencia solitaria, relativamente apartadas de otros miembros de la comunidad (2008, p. 8); lo cual no les impide

184 reunirse para visitas personales, faenas colectivas en el campo o fiestas y celebraciones de carácter religioso. 


\section{Las importaciones tecnológicas}

Las herramientas importadas tales como el arado, el hacha de metal, el machete, el pico, las navajas, las gubias, los encendedores, las barras de metal, los molinos metálicos para el maíz, las agujas y telas sintéticas han facilitado sus manualidades. Más aún, muchos animales domésticos han sido introducidos: los bueyes útiles para las labranzas, las gallinas, los carneros, las cabras, las vacas, los burros, las mulas y los caballos, cuya crianza está en el origen de la necesidad de las migraciones estacionales. Han descubierto así los productos de la cría de bovinos, ovinos y caprinos, como los quesos, la lana (en complemento de las fibras vegetales). Los españoles también les trajeron los abonos y fertilizantes, muy importantes para abonar los pedregales. El aporte del cultivo del trigo ha venido a suplir el del maíz en caso de hambruna. La introducción de las frutas como las manzanas, los chabacanos, membrillos y naranjas ha desempeñado un papel destacado en esta evolución. Esto les ha permitido mejorar sus cosechas. Más recientemente y aún en la actualidad, la goma de las llantas les sirve para confeccionar las suelas de sus huaraches o sandalias (en vez de emplear solamente pedazos de cuero no curtidos), lo que denota un progreso no despreciable para este pueblo andador y corredor. De este modo, podemos considerar esas aportaciones como una adquisición de libertades que les ha permitido diversificar su alimentación beneficiándose de carnes $^{27}$ y productos lácteos más nutritivos. No es por ello que han abandonado sus antiguas prácticas agrícolas, de caza y pesca. En este sentido, Coutarel (1996) habla de un sincretismo y hace hincapié en el uso del rifle y del palo de dinamita; pero también de la modernización de su artesanía, notablemente gracias a la llegada del curtido de pieles, del punto, de la confección de nuevas cestas. 


\section{El caso de Ciudad Juárez}

Con el propósito de comparar las encuestas realizadas en Cuauhtémoc con las condiciones de vida en Juárez, proponemos una síntesis del artículo de Luis Bautista Ricardo Cortez (20I7), sobre los 1500 indígenas que viven en esta urbe, de los cuales unos 600 son tarahumara, instalados en la Colonia Tarahumara (en la periferia) y en el km. 33 en la carretera que conduce a Casas Grandes. Han migrado de la Sierra por la desforestación importante, la sequía, la escasez de trabajo, la pobreza y las hambrunas (son puntos comunes). En la ciudad, los hombres obran como comerciantes, artesanos, cocineros, albañiles en su mayoría. Los hay que son empleados en los ranchos del Valle de Juárez. Pese a ello, hay mujeres y niños que siguen siendo enviados a mendigar $^{28}$. Los servicios públicos son insuficientes, excepto la escuela bilingüe (son otros puntos similares). Pero, aquí también, frecuentemente es un lugar de acoso, lo cual les obliga a las familias a vivir retiradas de la sociedad y eso les frustra. Por lo contrario, el autor de este artículo hace referencia a los estragos de la sociedad posmoderna: unos miembros de esta comunidad son víctimas del alcoholismo. Permaneciendo pobres, sufren de estar excluidos o muy poco incluidos y especialmente de las numerosas discriminaciones, humillaciones, de los gritos, las burlas, agresiones físicas debidas al racismo, pudiendo ser muy violentas y llevar a la muerte, tanto de parte de la sociedad como de las autoridades ${ }^{29}$. Por ejemplo, reciben insultos a causa de la ropa que llevan o simplemente porque son más morenos

186 que los mestizos. Así viven en el temor o el miedo de los otros por la falta de respeto para con ellos y eso representa en su opinión una privación importante, una pérdida de libertades. Sólo quienes han logrado librarse de eso vuelven a encontrar su libertad y se sienten más a gusto, estima R. Cortez. A pesar de todo, algunos quieren salir adelante, concretamente los niños o jóvenes que estudian y tienen 
ambiciones para cambiar su situación. Su elección de vida ciudadana parece ser irreversible en la medida en que han comprendido que consiste en su única oportunidad de evolucionar. El artículo llama la atención sobre una de las causas esenciales de esos comportamientos incívicos: la carestía de leyes de integración de estos pueblos indígenas a la sociedad y a la clase productiva. Despecho a todo eso, los ancianos se esfuerzan por mantener y perpetuar sus costumbres ancestrales para los jóvenes (como el mantenimiento de las danzas), este hecho viniendo a aminorar la deculturación. Como contrapartida, se han adaptado a la vida ciudadana y al día de la Madre, de Navidad, Halloween. En síntesis, anhelan ser mejor conocidos y sobre todo reconocidos, por lo mismo respetados, rasgo común con el estudio del caso de Cuauhtémoc.

\section{Conclusión: Debate sobre las perspectivas}

Si se adopta la perspectiva estricta de los etnólogos y antropólogos tradicionalistas, cuyo mayor interés es salvaguardar lo más posible a los pueblos y sus culturas originales, concepto que se opone al progreso y a la modernidad, se puede concluir sobre una situación de fracaso, como Maldonado lo ha puesto de realce: "Por desgracia, este cambio no parece superficial. Manipulados por la civilización, sus vidas y mentes se transforman paulatinamente adaptándose al consumismo. [...] Poco a poco su mente y su alma han sido atrapadas por el vértigo de la modernidad" (2009, p. 50). Hasta va más lejos afirmando que el indígena es utilizado con fines turísticos, su imagen siendo idealizada, aun mitificada, lejos de la realidad de este ser necesitado, con defectos y debilidades humanas. Por otro lado, todos esos cambios son profundos e irreversibles. 
Sin embargo, si se opta por un compromiso entre tradiciones preservadas y modernidad, se deprende que esta etnia ha sabido encontrar, en su mayoría y en cierta medida, un modus vivendi que le corresponde, de modo que se distinguen tres tipos de reacciones: los tradicionalistas que rehúsan cualquier concesión a la aculturación, atrincherándose más en el corazón de las montañas y evitando al máximo los contactos con los mestizos y los liberales; estos mismos, aculturados en diversos grados, se acomodan en ciertos cambios procedentes del exterior de su comunidad; y, al fin, los que deliberadamente abandonan (a veces definitivamente) la Sierra para migrar hacia las grandes urbes donde pueden estar sometidos a la ignorancia, la incomprensión, las ofensas y hasta el racismo y los malos tratos. Por eso, los tradicionalistas, consciente o inconscientemente, escapan de los males de las civilizaciones modernas y se protegen de ellos, conservando así lo más posible sus libertades originales, por encima de todo la de vivir en armonía con la naturaleza. En la década de los 90, ya no representaban más que alrededor de un $20 \%$ de la etnia (Coutarel, 1996, p. 139).

Empero, y a pesar de todos los aportes y las mejoras que les han permitido tener una vida mejor, esto no concierne a todos los individuos: los hay que padecen de hambrunas, restricciones $o$ privaciones de las libertadas evocadas, particularmente del avance de la civilización moderna provocando trastornos tales como aculturación, ladinización o mexicanización que pueden acarrear una deculturación

188 sicológica y material o bien una asimilación a la civilización.

La problemática relacionada con el indigenismo ha sacado a la luz su retraso evidente con respecto a la civilización moderna, pero sobre todo el olvido y el abandono de la sociedad nacional, impotente para extraerlos de sus condiciones miserables de vida y aún menos para 
integrarlos. Sobre este tema, el etnólogo y periodista Fernando Jordán, crítico respecto de ese "problema tarahumara", ha declarado:

Cuatro siglos de influencia cultural europea, I40 años de gobierno autónomo, 50 años de Revolución y io de política indigenista no han logrado hacer cambiar la tradición del tarahumara y, ni por asomo han conseguido mejorar su vida miserable ni propiciar su incorporación a nuestra civilización a nuestra sociedad (Jordán, 1948).

Incluso considera que este pueblo cuesta dinero a la Nación (y, de esta manera, a los contribuyentes) y que, a cambio, no participa para nada en el desarrollo económico y social (Jordán, 1989).

En realidad, se asiste a una modificación de cultura progresiva y en diversos niveles, junto con una pérdida de libertades ancestrales y una adquisición de nuevos derechos y libertades. La cuestión queda en si ¿esta sustitución se produce voluntariamente, en plena conciencia, o en contra de ellos, más o menos inconscientemente? Con consentimiento y el deseo de evolucionar o bien si sufren de lleno esa destribalización. Jordán (1954), para quien su porvenir está condicionado indudablemente por la evolución y el progreso, el medio o el método menos violento es la educación tal como los jesuitas la han impartido en las misiones, escuelas e internados.

Por último, se plantea otra pregunta: ¿cuál es la mejor perspectiva que se puede adoptar para ellos? Para aprehender este aspecto, hay que tener en cuenta dos posturas: la de la sociedad mestiza mexicana y la de los tarahumaras. Para la primera, existen dos opciones: abandonarlos a sus condiciones de indios "primitivos" con la intención de preservarles lo mejor posible, sin perjuicio de que se vuelvan excluidos; esta concepción no es válida sino para el porcentaje de autóctonos más 
reticentes a cualquier cambio y que desean vivir en autarquía. Mas, en vista de las condiciones de vida muy difíciles que soportan a duras penas, ¿es razonable dejarles así? La segunda perspectiva consiste en ayudarles, de la mejor forma posible, a vivir mejor. Para una muy amplia mayoría de esta etnia, el interés en juego es a ese nivel. La realidad es una aculturación en diferentes grados, en ocasiones una asimilación de miembros de esta comunidad por los mestizos.

Por su cuenta, se puede establecer un paralelismo con las dos opciones citadas y, en cuanto a los hechos, resultan ser muy influenciables, adoptando fácilmente los usos y costumbres modernos a los cuales están cada vez más expuestos. A ese respecto, el fotógrafo Pedro Tzontémoc, quien notó esas transformaciones, esa mexicanización, está para salvar no su ropa ni aun su idioma sino su concepción de la vida. Dedujo de ello que, a fuerza de irse abriendo al mundo exterior, se hallan en una fusión de las culturas tarahumara y mestiza, forma de una nueva cultura. Así se explicó: "aunque muchos tarahumaras viven como mestizos, tienen un fuerte arraigo cultural. Tienen una doble vida porque sienten a la vez rarámuris y mestizos (Coutarel, I996, pp. I89I90), como hemos podido observarlo en los municipios de Cuauhtémoc y Juárez. En resumen, esta situación sociocultural puede representar un compromiso más bien favorable. Y si se les consulta sobre esta cuestión, no parecen estar opuestos a una educación nacional siempre y cuando integre su propia cultura. Para dar una opinión representativa de dicha comunidad, el líder Juan Gardea García ha declarado: “queremos la

190 educación pero que tenga un espíritu indígena, orientada a nuestra cultura (Crece en Chihuahua la generación..., 20I7). Ha deplorado también el que los maestros exteriores, por lo general, dicten cursos sin tomar en cuenta esta reivindicación de transmitir las tradiciones y creencias locales. 


\section{Referencias}

Almodóvar, A. (2015, julio 9). El racismo del que no se habla, la cuestión Tarahumara en Ciudad Juárez. La Izquierda Diario. Disponible en: http://www.laizquierdadiario.mx/El-racismo-del-que-no-sehabla-la-cuestion-Tarahumara-en-Ciudad-Juarez

Allouette, P. (200o). Mexique: Le Chemin de Fer Chihuahua-Pacifique: Voie de communication, Histoire et Société (De I849 à nos jours), [thèse de doctorat, sous la direction du Professeur Pierre-Luc Abramson]. Université de Perpignan, Perpignan, France.

Artaud, A. (2004). Euvres. Paris : Quarto Gallimard.

Bennett, W.C. y Zinngg, R.M. (I986). Los Tarahumaras, una tribu india del Norte de México. México: Instituto Nacional Indigenista.

Coutarel, J. (1996). Les Tarahumaras : le rêve d'un homme, la réalité de tout un peuple [mémoire de maîtrise, sous la direction de Louis Panabière et Pierre-Luc Abramson]. Université de Perpignan, Perpignan, France.

Crece en Chihuahua la generación de chabochis entre tarahumaras. (2017). Las Noticias México. Disponible en: http://www.lasnoticiasmexico.com/I84527

De la Peña, M.T. (1945). La mexicanización del indio. Un problema económico. Revista de economía, v.I., pp.3-34.

INEGI (Instituto Nacional de Estadística y Geografía). (20Io). Censo de Población y Vivienda 20IO. Disponible en: https://www.inegi.org.mx/programas/ccpv/20Io/default.html\#T abulados

Jesuitas en Tarahumara: Trabajo de la comunidad de Jesuitas en la Sierra Tarahumara. (2017). Disponible en: https://jesuitasentarahumara.wordpress.com/ 
Jordán, F. (I948, diciembre 24). Ejemplares vivos de los hombres de la prehistoria. Mañana.

Jordán, F. (1954, julio 24). ¿Serán los indios el problema? Es posible que los indigenistas sean un problema mayor. Siempre, (57).

Jordán, F. (I989). Crónica de un país bárbaro. $7^{\mathrm{a}}$ Ed. Chihuahua, México: Centro Librero La Prensa.

Maldonado Ortíz, C. (2009). Rarámuri: Libertad en ocaso. Recuerdos de la Tarahumara. Bloomington, Indiana: AuthorHouse.

Mayorga Ordóñez, P. (2012). Huyen de la sierra por sequía y narcoviolencia. En la miseria, mujeres indígenas que migran a ciudad de Chihuahua. cimacnoticias.com.mx. Disponible en: http://www.cimacnoticias.com.mx/node/6IO7I

Mcdougall, C. (20I2). Born to run (Né pour courir). Chamonix : Éditions Guérin.

Plancarte, F.M. (1954). El problema indígena tarahumara, memorias del Instituto Nacional Indigenista. México: INI.

Ricardo Cortez, L.B. (20I7). Indígenas en la ciudad: discriminados y pobres. netnoticias.mx. Disponible en: http://netnoticias.mx/reportajes/indigenas/index.php

Rodríguez Villegas, M. (s/f). Diccionario español-tarahumara en línea AULEX. Disponible en: http://aulex.org/es-tar/

Sariego Rodríguez, J.L. (2009). De minas, mineros, territorios y protestas sociales en México: los nuevos retos de la globalización. Cahier Des Amériques Latines, p. I73-192. Disponible en: https://cal.revues.org/I435?lang=es

Sil International México. (20I7). «Diccionario tarahumara actualizado» 2016 [Diccionario tarahumara de Samachique, Chihuahua, México-edición especial corregida y actualizado-1993]. 
Disponible

en

http://www.mexico.sil.org/es/resources/archives/68IIO

Wampler, J. (1978). La Barranca del Cobre de México. La Región e Historia de los Indios Tarahumaras y de los F. C. Chihuahua al Pacífico. Berckeley.

Notas

${ }^{\text {I }}$ Esta cabecera municipal se ubica Ioo kilometros al noroeste de la capital del estado de Chihuahua.

${ }^{2}$ Aunque su endónimo es rarámuri, el uso ha generalizado el empleo del sustantivo y del adjetivo «tarahumara». En su lengua, rarámuri significa también el nombre de su idioma y no ha sido señalado antes del siglo XIX, según Maldonado (2009). Por comodidad, seguiremos nombrándoles de la segunda manera.

${ }^{3}$ Término tarahumara que designa «mestizo», según Rodríguez (s/f).

${ }^{4}$ El Dr. Carlos Maldonado Ortíz es médico, fotógrafo, montañista, políglota, escritor, administrador empresarial y viajero.

${ }^{5}$ A saber el «Diccionario español-tarahumara» y el Sil International México.

${ }^{6}$ Este trabajo fue premiado por la Sociedad de Hispanistas Franceses. Traducción libre de P. Allouette.

${ }^{7}$ Pueblos fundados en torno a una pequeña iglesia y una plaza.

8 El autor menciona, en la misma página, que esta obra de cristianización comenzó hacia I607-I608 y que "fue interrumpida [un año] en I6I6 por la sublevación de los indios tepehuanes." Evoca también, en la p. II6, la pérdida progresiva total de las creencias y prácticas ancestrales "en las zonas más propensas a la evolución, 
[donde] la evangelización ha dado lugar a una forma de sustitución cultural." Traducción libre de P. Allouette.

${ }^{9}$ Borracheras con tesgüino, tipo de cerveza de maíz que fabrican.

${ }^{10}$ Traducción libre de P. Allouette.

${ }^{\text {II }}$ Tales como los Témoris, Chínipas, Guazapares y Tubares.

${ }^{12}$ Entre 1994 y 2010.

${ }^{13}$ Este concepto está definido por el antropólogo Juan Luis Sariego Rodríguez de la manera siguiente: "La mexicanización del indio, entendida esta en términos más culturales que biológicos, significa aceptar con realismo el ineludible proceso histórico que enfrentaba al indígena ante el dilema de desaparecer o asimilarse a la cultura mestiza" (2009). Luego, retomando a De la Peña, recuerda los fundamentos económicos necesarios a este proceso: "las estrategias más efectivas para acelerar esta mexicanización del indio -más avanzada en los estados norteños de la República, tenían que ser de carácter económico y consistían en fomentar la construcción de vías de comunicación en las regiones indígenas, alentar su colonización mestiza en actividades como la minería, modernizar las actividades agropecuarias y extender el aparato educativo" (1945, p. 202).

${ }^{14}$ Esas terracerías sirven para transportar los estupefacientes hasta aviones, ubicados más al norte, para transportar esas drogas a los Estados Unidos.

${ }^{15}$ Entre 2000 y 2008, el precio del oro creció un II7\% (Sariego, 2009).

${ }^{16}$ En 1954 había II3 pueblos y 915 rancherías (Sariego, 2009).

$194{ }^{17}$ La directora de la Coordinadora Estatal de la Tarahumara, Eloisa Robledo, ha citado un alto porcentaje - $40 \%$ - de detenidos indígenas en las cárceles de la Sierra (Crece en Chihuahua la generación de chabochis entre tarahumaras, 2017).

${ }^{18}$ Cerca de las riberas del río Conchos, al pie de la Sierra Madre Occidental. 
${ }^{19}$ Aunque las reservas faunísticas han disminuido mucho debido a la extinción de las especies.

${ }^{20}$ El autor expone también los dominios a los cuales se unen esos rasgos: "se refieren al núcleo de la cultura material, a las concepciones y prácticas sobre la salud y la enfermedad, la estructura y función de las fiestas tradicionales o "nativas", los ceremoniales de vida y muerte, la figura de los shamanes y hechiceros, los términos y estructuras del parentesco, las nociones y prácticas relativas a la propiedad y la herencia, los juegos, los deportes y la valoración sobre el consumo festivo del tesgüino y del peyote" (Sariego, 2009, p. 77).

${ }^{2 I}$ Ayudados por laicos, están activos desde 2011 y han creado el blog "Jesuitas en Tarahumara: Trabajo de la comunidad de Jesuitas en la Sierra Tarahumara», actualizado hasta 2017. En su portal, dan un resumen de sus misiones, principalmente para 70 niños, tocándoles a 90 familias: "Los Centros Culturales complementan la educación pública. Su objetivo es fomentar espacios de profundización de la vida y cultura rarámuri, por medio de la alfabetización, actividades artísticas y musicales, para que niños, niñas y jóvenes indígenas puedan desarrollar aptitudes que faciliten una mejor interacción dentro y fuera de su cultura sin perder su identidad." https://jesuitasentarahumara.wordpress.com/. También han abierto una página en Facebook y una cuenta en YouTube (cuyos enlaces están al final del artículo del 27/02/2017, en el URL mencionado).

${ }^{22}$ Deseamos dar las gracias a los estudiantes de la Universidad Autónoma de Ciudad Juárez, División Cuauhtémoc, bajo la coordinación de la Dr. Patricia Islas Salinas, que han realizado estas encuestas de terreno.

${ }^{23}$ Contaba con I68 mil 482 habitantes en 20I5, según el Instituto Nacional de Estadística y Geografía (INEGI, 20I0).

${ }^{24}$ Sariego intitula una parte de su trabajo así: El sueño del mestizaje (2009, 197). 
${ }^{25} 2000$ a 3000 obreros trabajaban en promedio en las obras, la mayor parte eran tarahumara (Wampler, 1978).

${ }^{26}$ Véase Allouette (200o) pp. 449-48o.

${ }^{27}$ Consumidos durante las ceremonias y festividades.

${ }^{28}$ Como en la Sierra, las mujeres fabrican y venden también su artesanía. Pueden realizar igualmente quehaceres siendo empleadas pero, según Patricia Mayorga Ordónez que retoma a la antropóloga Ana Elena Loreley Servín, especialista en migración indígena en el estado de Chihuahua, la mayoría prefiere renunciar. Separadas o viudas, invitadas por su familia, migran a Chihuahua con el objetivo de cambiar de vida. Se instalan en zonas marginadas, uniéndose a las personas oriundas de su región, en las mismas condiciones que en Ciudad Juárez. Según esta antropóloga, como no quieren renunciar a su libertad de movimiento, generalmente, se niegan a sendentarizarse en hogares o para empleos industriales. Le dan mucha importancia a su autonomía y se oponen a la sumisión y dependencia para con empleadores. De ahí el hecho de que viven de la caridad (el famoso Kórima o donación/reparto) de sus semejantes y de la limosna (Mayorga, 20I2).

${ }^{29}$ El caso de un joven tarahumara de 22 años, víctima de un homicidio perpetuado por policías de Ciudad Juárez, en 20I5, ha sido objeto de un artículo (Almodóvar, 2015).

Este artículo se publica bajo una licencia de Creative Commons Reconocimiento-NoComercial 4.0 Internacional, y puede ser usados gratuitamente para fines no comerciales, dando los créditos a los autores y a la revista.

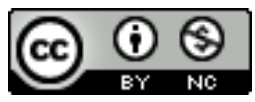

Debates por la Historia - Artículos 